http://revistaseletronicas.pucrs.br/ojs/index.php/aviation doi): http://dx.doi.org/10.15448/2179-703X.2015.1.21380

\title{
Risco biológico na aviação
}

\section{Biological risk in aviation}

\author{
Diego Rigamonte Vasconcelos ${ }^{1}$, Roberto Márcio dos Santos² \\ 1 Acadêmico do curso de graduação em Ciências Aeronáuticas pela PUC-GO. < diegorvas@gmail.com> \\ 2 Mestre em Segurança de Aviação e Aeronavegabilidade Continuada pelo ITA. Mestre em Psicologia pela UFRGS. Especialista em Metodologia do Ensino \\ de Educação Física pela UFRGS. Graduado em Educação Física pela ESEFEGO. Controlador de Tráfego Aéreo pela Força Aérea Brasileira. \\ Professor no curso de Ciências Aeronáuticas da PUC-GO. <rob.marcio@hotmail.com>
}

\begin{abstract}
RESUMO
Este artigo pretende alertar o público em geral e, em especial, os profissionais da aviação e da saúde quanto à perigosa influência da aviação na propagação de doenças infecciosas pelo mundo. Mostra-se, aqui, como o transporte massivo e constante de pessoas por todas as partes do planeta pode atuar como um 'gatilho epidêmico', disseminando doenças contagiosas muito rapidamente por todo o globo, e aponta-se a necessidade atual de se desenvolver um sistema preventivo mais eficaz, para um melhor gerenciamento desse risco.
\end{abstract}

Palavras-CHAvE: Aviação; Saúde; Doenças; Gatilho epidêmico

\section{ABSTRACT}

This article intends to alert the general public, specially aviation and health professionals, to the dangerous influence aviation exerts on the propagation of infectious diseases around the world. It's shown here how the massive and constant people transportation to all parts of the planet can act as an 'epidemic trigger', spreading contagious diseases very quickly throughout the globe. Furthermore, it's pointed out that there is a current need to develop a more effective prevention system in order to manage this risk more effectively.

KEYwORDS: Aviation; Health; Diseases; Epidemic trigger

Pontifical Catholic University of Rio Grande do Sul Porto Alegre, RS, Brazil

Editor

Thaís Russomano

Microgravity Centre PUCRS, Brazil

Executive Editor

Rafael Reimann Baptista

Faculdade de Educação Física e Ciências do Desporto, PUCRS, Brazil

e-ISSN: 2179-703X

\section{Corresponding Author:}

Diego Rigamonte Vasconcelos

<diegorvas@gmail.com>

Received: July 20, 2015

Accepted: October 21, 2015

(C) 2015 EDIPUCRS 


\section{Introdução}

A aviação representa um grande salto da humanidade sob os mais diversos aspectos, mas com ela vieram também riscos que devem ser cuidadosamente gerenciados. Dentre eles, está o risco biológico, objeto de análise deste trabalho, que a NR $32^{1}$ (1) define como "a probabilidade de exposição a agentes biológicos", que são, por sua vez, "micro-organismos, geneticamente modificados ou não; culturas de células; parasitas; toxinas e príons ${ }^{2 "}$. No contexto da aviação, o risco biológico é, em particular, a suscetibilidade do corpo humano a doenças e outras complicações causadas por micro-organismos que encontram condições favoráveis para a sua proliferação e manifestação no interior das cabines das aeronaves.

Primeiramente, explica-se como a aviação comercial contribui para a disseminação de doenças pelo mundo. Em seguida, é feita uma abordagem sobre as medidas que devem ser tomadas pelo Comandante da Aeronave (CMTE) em caso de suspeita de ameaça biológica a bordo, com base nos regulamentos atuais. $\mathrm{Na}$ continuação, trata-se da íntima relação entre a aviação e a propagação do vírus ebola, situação ocorrida muito recentemente, que foi motivo de grandes preocupações dos governos de todo o mundo. $O$ tema seguinte diz respeito às formas de contágio durante o voo, com base em pesquisas conduzidas por diversas instituições e, por último, é feita uma crítica sobre como a questão do risco biológico na aviação é tratada nos dias de hoje.

Este artigo foi elaborado, principalmente, com base em: textos didáticos sobre medicina e biologia; periódicos de circulação internacional; regulamentos pertinentes, no âmbito da aviação civil; pesquisas quantitativas e protocolos de segurança relativos à saúde.

\section{Aviação: um gatilho epidêmico}

O principal problema que a aviação oferece, relacionado ao risco biológico, é ser um gatilho em potencial para a propagação de epidemias pelo globo, devido ao rápido, massivo e incessante transporte de passageiros e cargas por todo o mundo. Ela faz com que haja muito mais interação entre pessoas distantes. Assim, uma doença que venha a surgir num local muito afastado pode se alastrar muito rapidamente pelo mundo, de forma que a atual tecnologia médico-farmacêutica não tenha tempo suficiente

\footnotetext{
${ }^{1}$ Elaboradas pelo Ministério do Trabalho, as Normas Regulamentadoras (NRs) visam promover a segurança e a saúde dos trabalhadores.

2 Príons: moléculas proteicas infecciosas causadoras de doenças ao sistema nervoso (3) (Cardoso, 2015).
}

para desenvolver contramedidas, antes que danos significativos já tenham sido causados (2).

Além da interação entre pessoas em escala global, há outros fatores ligados à aviação que também contribuem para o alastramento de infecções. Um passageiro portador de uma doença pode ter seu quadro agravado durante o voo, devido a razões de ordem psicológica, como ansiedade ou nervosismo, e das demais condições proporcionadas pelo ambiente da cabine, como pouca oxigenação, baixa umidade relativa do ar e variações súbitas de pressão e força $\mathrm{G}^{3}$, que acarretam estresse e fadiga ao organismo (4).

Todos esses fatores aumentam também a vulnerabilidade do organismo humano a doenças infecciosas, já que viroses, em particular, tendem a se espalhar com maior facilidade em ambientes de baixa umidade, devido ao comprometimento do funcionamento das membranas mucosas, importantes ferramentas do sistema imunológico. E a fadiga provocada pela exposição do corpo a altitudes elevadas prejudica também a atuação de suas defesas. Por esses motivos, não é recomendável, por exemplo, que recémnascidos com menos de três meses de vida façam viagens de avião, já que não possuem ainda o sistema imunológico suficientemente fortalecido (4).

\subsection{Atuação do Comandante da Aeronave em caso de suspeita de ameaça biológica}

Diante dessas circunstâncias, acaba surgindo uma situação um tanto delicada, pois, segundo o Art. 168 do Código Brasileiro de Aeronáutica (5), "O comandante exerce autoridade sobre as pessoas e coisas que se encontram a bordo da aeronave, e poderá desembarcar qualquer delas, desde que comprometa a boa ordem, a disciplina ou ponha em risco a segurança da aeronave ou das pessoas e bens a bordo". Então, se ele suspeita que um passageiro tenha uma doença que possa colocar em risco a sua saúde ou a de outros passageiros durante o voo, poderá impedi-lo de voar.

Mas deve-se tomar cuidado com a forma como essa medida é adotada. Se o passageiro se sentir desrespeitado ou humilhado diante de uma situação dessas, poderá recorrer à justiça, segundo a Associação Nacional em Defesa dos Direitos dos Passageiros de Transporte Aéreo (ANDEP). Assim, compete ao CMTE tomar a decisão final, mas ele deverá estar atento a isso, sendo cauteloso com o tratamento dado ao passageiro e não passando dos limites do que é considerado adequado

\footnotetext{
${ }^{3}$ Força G: unidade de aceleração correspondente à força gravitacional da Terra, que representa a quantidade de aceleração da gravidade que está sendo exercida sobre um corpo (7).
} 
e respeitoso. Ficou conhecido, em 2013, o caso da coreógrafa brasileira Deborah Colker, que quase foi impedida de voar acompanhada de seu neto, por ele ser portador de uma doença denominada epidermólise bolhosa - doença não contagiosa, caracterizada pelo aparecimento de bolhas na pele, membrana e mucosa. Para ela, o tratamento recebido foi extremamente vergonhoso. Nesse caso, caberia então uma ação judicial (6).

Frente a esse quadro, recomenda-se que passageiros que apresentem doenças contagiosas, cardíacas, respiratórias ou pós-operatórios portem um atestado médico que garanta que não estarão colocando em risco a sua própria saúde ou a saúde dos demais passageiros do voo. A médica Vânia Melhado, presidente da Sociedade Brasileira de Medicina Aeroespacial (SBMA), ao ser indagada sobre o assunto, afirmou: "A mesma doença pode deixar uma pessoa inapta a viajar em um momento e apta em outro". A catapora e a tuberculose são bons exemplos dessa situação, pois inviabilizam a viagem apenas quando estão em estágio transmissível, não representando perigo quando deixam de ser contagiosas. Daí a importância do atestado para comprovar essa situação (6).

É comum encontrar nos sites das próprias companhias o Formulário de Informação Médica (MEDIF), que é um formulário relativo ao comportamento de doenças durante um voo, padronizado internacionalmente pela Associação Internacional de Transporte Aéreo (IATA), órgão que representa a maioria das linhas aéreas do mundo. Ele deverá ser preenchido pelo médico do passageiro e entregue à companhia aérea antes da viagem, e o departamento médico da mesma avaliará o caso, determinando se o passageiro poderá ou não embarcar no voo. Caso o passageiro opte por levar um atestado comum, nele deverá constar categoricamente que a viagem não agravará o quadro de sua doença, e que ela não representa risco de contágio para os demais passageiros (8).

A Organização de Aviação Civil Internacional (OACI), que regulamenta mundialmente a aviação civil por meio de seus 19 Anexos, estabelece no Anexo 2: Regras do Ar, regulamentado no Brasil pela ICA 100-12 - Instrução do Comando da Aeronáutica (9), que o CMTE reporte ao órgão prestador do Serviço de Tráfego Aéreo - Órgão ATS - qualquer suspeita de passageiro com doença transmissível ou qualquer outro risco à saúde pública, com o intuito de facilitar e agilizar, no aeródromo de destino, a provisão de equipe médica devidamente preparada e equipamentos específicos para a situação. Essa mensagem deve incluir: identificação da aeronave, aeródromo de partida, aeródromo de destino, hora estimada de chegada, número de pessoas e de casos suspeitos a bordo e a natureza do risco à saúde pública, se for conhecida. O órgão ATS em questão deve, então, repassar a informação para o órgão ATS de partida, a fim de evitar a propagação da enfermidade a partir de outras aeronaves que partam do mesmo aeródromo; para o órgão ATS de destino, que deverá informar à administração do aeroporto, relatando a necessidade de contato com o órgão de saúde pública competente e para o operador da aeronave, que pode ser, por exemplo, uma companhia aérea.

Já no Anexo 9 - Facilitações (10), é previsto que passageiros com febre $-38^{\circ} \mathrm{C}$ ou $100^{\circ} \mathrm{F}$ de temperatura corporal, ou mais - associada a outros sintomas, como: mal-estar notório, tosse persistente, respiração comprometida, diarreia, vômito persistente, erupções cutâneas, cicatrizes ou sangramento sem injúrias prévias devem chamar a atenção da tripulação para potencial risco biológico. Se constatado o perigo, será considerado caso de doença comunicável a bordo, e o CMTE deverá informar prontamente ao controlador, na forma descrita no parágrafo anterior. É previsto também que aeronaves que requerem ao menos um tripulante de cabine - comissário - devem conter pelo menos um kit de equipamentos médicos. Esse kit deverá ser utilizado para higienização de algum corpo potencialmente infeccioso e para proteger a tripulação de possível contágio em decorrência do contato com fluidos provenientes do mesmo, como sangue e urina.

Há também, no Anexo 9 (10), referências ao denominado Cartão de Saúde Pública Localizador de Passageiro. Este consiste basicamente num formulário desenvolvido pela Organização Mundial da Saúde (OMS), que deve ser preenchido pelos passageiros durante o voo ou no momento do desembarque e entregue à autoridade competente, quando desconfiarse da existência de passageiros com doença comunicável no voo. Ele conterá informações que permitirão às autoridades públicas rastrearem rapidamente qualquer pessoa que tenha se exposto a maiores riscos de contágio durante a viagem, levando em conta, principalmente, a localização de seu assento, que será identificado em um 'mapa de risco', desenvolvido por especialistas da área de saúde. Trata-se de uma medida de controle de saúde pública que, segundo a OACI, IATA e OMS, deve ser prontamente utilizada, caso surja alguma epidemia em qualquer país com o qual realizem-se operações aéreas.

O item 8.16 do Anexo 9 (10) determina que o Estado Contratante ${ }^{4}$ deve estabelecer um plano nacional de aviação como medida preventiva, em caso de surto de doença contagiosa que coloque em risco

\footnotetext{
${ }^{4}$ Forma como é designado um país participante do tratado da OACI.
} 
a saúde pública. A primeira nota do item informa que orientações para tal são encontradas no site da própria OACI, na página Aviation Medicine, e a segunda, que órgãos de tráfego aéreo, juntamente com aeródromos, devem estabelecer, respectivamente, planos de contingência e planos de emergência em aeródromos para o risco em questão, conforme os Anexos 11 Serviços de Tráfego Aéreo e 14 - Aeródromos.

O CMTE também deverá estar atento a procedimentos e protocolos estabelecidos pela própria companhia aérea. No Brasil, as companhias adotam certas políticas de segurança, elaboradas com base em resoluções do Conselho Federal de Medicina e dos Órgãos de Vigilância Sanitária (5). O CMTE deverá, ainda, consultar as Publicações de Informações Aeronáuticas (AIPs) dos países de origem e destino para se informar de seus respectivos requerimentos legais relacionados à saúde. Consta na AIP Brasil (11), por exemplo, que não se aplicam medidas de saúde pública às aeronaves que operem neste País, a não ser que sejam provenientes de área infectada. Nesse caso, a aeronave deverá ser desinfetada, quando na chegada, pela Autoridade de Saúde local, com suas portas e janelas fechadas e sistemas de ventilação desligados, durante todo o procedimento.

\section{Ebola e aviação}

Durante a crise do ebola, ocorrida em 2014, a OMS definiu, em uma reunião de seu Comitê de Emergência, em Genebra, que contou com representantes de seus 194 países membros, diversos critérios visando dificultar a propagação do vírus (12). Nos países onde foram registrados casos da doença, principalmente aqueles mais afetados, como Guiné, Libéria e Serra Leoa, passageiros que apresentassem sintomas da doença deveriam ser examinados antes de embarcar, e não seria permitido que nenhuma pessoa viajasse com algum mal-estar que pudesse ser o ebola, a não ser em caso de transferência médica.

Segundo Keiji Fukuda, adjunto de Margaret Chan, diretora geral da organização: "A OMS não recomenda a proibição de viagens e comércio, a menos que se trate, de maneira específica, de pessoas infectadas ou que estiveram em contato com um doente" (13).

$\mathrm{Na}$ prática, porém, foi bem diferente. Diversas companhias aéreas cancelaram seus voos a países em crise, mostrando que têm bastante autonomia para adotar medidas próprias quando o assunto é a segurança de seus passageiros e funcionários, a começar pela Emirates, que suspendeu, no dia 2 de agosto de 2014, seus voos para a Guiné. Logo em seguida, dia 5 de Agosto de 2014, a British Airways suspendeu suas operações para Serra Leoa e Libéria por um mês, informando que tomou essa providência devido à condição da saúde pública, que se encontrava deteriorada nesses dois países, e que a segurança de suas tripulações, passageiros e equipes em solo seriam sempre a prioridade da companhia. Assim, segundo o porta-voz da empresa, clientes que tinham viagem marcada poderiam solicitar reembolso, ou remarcá-la para uma data posterior (14). Em sequência, a Korean Air suspendeu, dia 14 de Agosto de 2014, seus voos para o Quênia, muito embora nenhum caso do ebola tivesse sido relatado nesse País até então. Foram suspensas também as operações da companhia ASKY, na Nigéria, após a chegada do americano Patrick Sawyer, que estava infectado e veio a falecer pouco tempo depois (15).

Sawyer contraiu a doença na Libéria, quando cuidava de sua irmã, que portava ebola. Ele já apresentava os sintomas da doença antes mesmo de tomar seus dois voos, que o colocaram em contato com 59 pessoas: o primeiro, da Libéria para Togo, pela ASKY Airlines, e o segundo, de Togo para Lagos, capital nigeriana (16). Segundo a Autoridade de Aviação Civil da Nigéria (NCAA), a companhia aérea ASKY não demonstrou qualquer capacidade para prevenir a chegada de passageiros contaminados à Nigéria. O governo nigeriano determinou, por esse motivo, a suspensão de suas operações em seu território (17).

Segundo Corrêa (18), pesquisadores analisaram dados sobre tráfego aéreo em 220 países com o intuito de prever possíveis padrões de propagação da doença pelo mundo e, devido à grande intensidade de circulação de aeronaves nos aeroportos do Rio de Janeiro e São Paulo, o Brasil foi perigosamente considerado a porta de entrada para o vírus na América Latina.

\subsection{Medidas de controle em aeroportos visando conter a propagação do ebola}

Nos países africanos mais afetados pela epidemia, os passageiros eram, desde cedo, submetidos a testes que visavam detetar a doença. No momento do embarque, respondiam a questionários relativos ao ebola e tinham suas temperaturas aferidas por termômetro infravermelho. Em caso de qualquer suspeita de ebola, eram impedidos de embarcar. Mas foi somente após a doença ter chegado a países de outros continentes que governos de outras partes do mundo se alertaram para o seu perigo. Consequentemente, esses procedimentos passaram a ser realizados em diversos aeroportos internacionais, de vários outros países. Dois casos que contribuíram para o alarme internacional e ficaram mundialmente conhecidos foram o do liberiano 
Thomas Duncan, ocorrido nos EUA, e o de Theresa Romero, na Espanha (19).

Romero, enfermeira que foi contaminada na própria Espanha, quando tratava de um paciente infectado proveniente de Serra Leoa, é hoje uma das sobreviventes da doença. Mas o caso de Duncan foi diferente. Tendo adquirido ebola ainda na Libéria, embarcou num voo com destino aos EUA sem dificuldades, não sabendo sequer que estava infectado. Passou pela checagem de temperatura três vezes antes do embarque, conforme os procedimentos adotados naquele País: no portão, antes de adentrar o estacionamento do aeroporto; no terminal e no momento do embarque, tendo respondido 'não' às perguntas do questionário relativas aos sintomas da doença e ao contato físico recente com portadores. Porém, o longo período de incubação do vírus - tempo desde a infecção até o aparecimento dos sintomas -, que varia de 2 até 21 dias, fez com que todos esses testes fossem ineficazes para o liberiano, que não apresentou, no momento em que foram realizados, nenhum dos sintomas da doença. Ele só veio a desenvolvê-los uma semana após a sua chegada nos EUA, onde veio a falecer poucos dias depois, e contagiou dois enfermeiros que lhe cuidavam (20).

Logo após esses acontecimentos, esses mesmos procedimentos de controle passaram a ser realizados também em aeroportos dos EUA, a começar pelo aeroporto JFK, em Nova York, estendendo-se posteriormente para outros aeroportos internacionais: Chicago O'Hare, Washington Dulles, Atlanta Hartsfield-Jackson, e Newark Liberty, em Nova Jersey. Funcionários norte-americanos da imigração calcularam que cerca de 150 pessoas viajavam diariamente de um dos três países que sofriam com surto do ebola - Guiné, Libéria e Serra Leoa - com destino aos EUA, e que 95\% delas desembarcavam em um desses cinco aeroportos. Muito embora não haja voos diretos entre esses países e os EUA, funcionários do departamento americano de Alfândega e Proteção de Fronteiras (CBP) conseguem determinar a proveniência exata de cada passageiro, ainda que ele tenha feito diversas conexões (21).

No Reino Unido, as medidas passaram a ser adotadas nos dois mais importantes aeroportos do País: Heathrow e Gatwick, ambos em Londres. A França, por sua vez, passou a realizar as triagens no aeroporto Charles de Gaulle, em Paris (21).

Uma série de críticas foi feita a essas medidas. Com relação à aferição de temperatura, levantou-se a possibilidade de o passageiro ingerir medicamentos que disfarçassem os sintomas da doença, inclusive a febre. Quanto ao questionário, passageiros poderiam simplesmente mentir para não levantarem suspeitas. Mas as mais alarmantes preocupações foram, sem dúvidas, concernentes ao já abordado longo período de incubação do vírus, fator decisivo que poderia simplesmente tornar inúteis todos esses procedimentos de segurança, como aconteceu no caso de Duncan (21).

Até o momento, a única forma segura de inspeção que se conhece e que contorna todas essas dificuldades é a realização de exames de sangue, pois não deixam dúvidas quanto à presença do vírus. Mas, para isso, é necessário que haja laboratórios nos locais em que se deseja fazer as análises, tornando esse procedimento muito difícil em aeroportos. Além disso, o grande número de passageiros a serem submetidos aos exames inviabiliza ainda mais essa opção (22).

\subsection{Procedimentos estabelecidos no Brasil para casos suspeitos de ebola em aeronaves}

No Brasil, o Ministério da Saúde estabeleceu, durante a crise de ebola, uma série de procedimentos a serem adotados em caso de suspeita de passageiro infectado, por meio do Protocolo de Vigilância e Manejo de Casos Suspeitos de Doença pelo Vírus Ebola (23). São eles: informação prévia ao aeroporto de destino que, por sua vez, acionaria imediatamente o Posto da Agência Nacional de Vigilância Sanitária (ANVISA) mais próximo. Este iniciaria os procedimentos necessários para a avaliação do caso, acionando o Serviço de Atendimento Móvel de Urgência (SAMU) ou outro serviço indicado pela Secretaria Estadual de Saúde em questão. Se fosse considerado realmente caso suspeito e se o paciente estivesse em condições de remoção, deveria ser iniciado um transporte aeromédico. O paciente seria transportado diretamente da aeronave em que chegou até a aeronave que o levaria ao hospital de referência nacional - Instituto Nacional de Infectologia Evandro Chagas/Fiocruz, RJ. Se não fosse possível o transporte àquele hospital, o paciente deveria ser conduzido ao hospital de referência estadual. Em seguida, uma equipe do Posto da Anvisa entrevistaria passageiros e tripulantes para a identificação de contactantes - pessoas sentadas imediatamente próximas ao suspeito, acompanhantes ou qualquer outra que tenha tido algum tipo de contato corpóreo - que, por sua vez, seriam acompanhados por profissionais da Secretaria Estadual de Saúde. Por último, seria feita a limpeza e desinfecção da aeronave, seguindo à risca os procedimentos constantes no documento denominado Plano de Contingência e Resposta para Emergência em Saúde Pública para Pontos de Entrada, da ANVISA, que contém todas as orientações para sua execução. 
Figura 1. Fluxograma do procedimento a ser seguido no Brasil em caso de risco biológico em aeronave (23)

\section{Aeroporto}

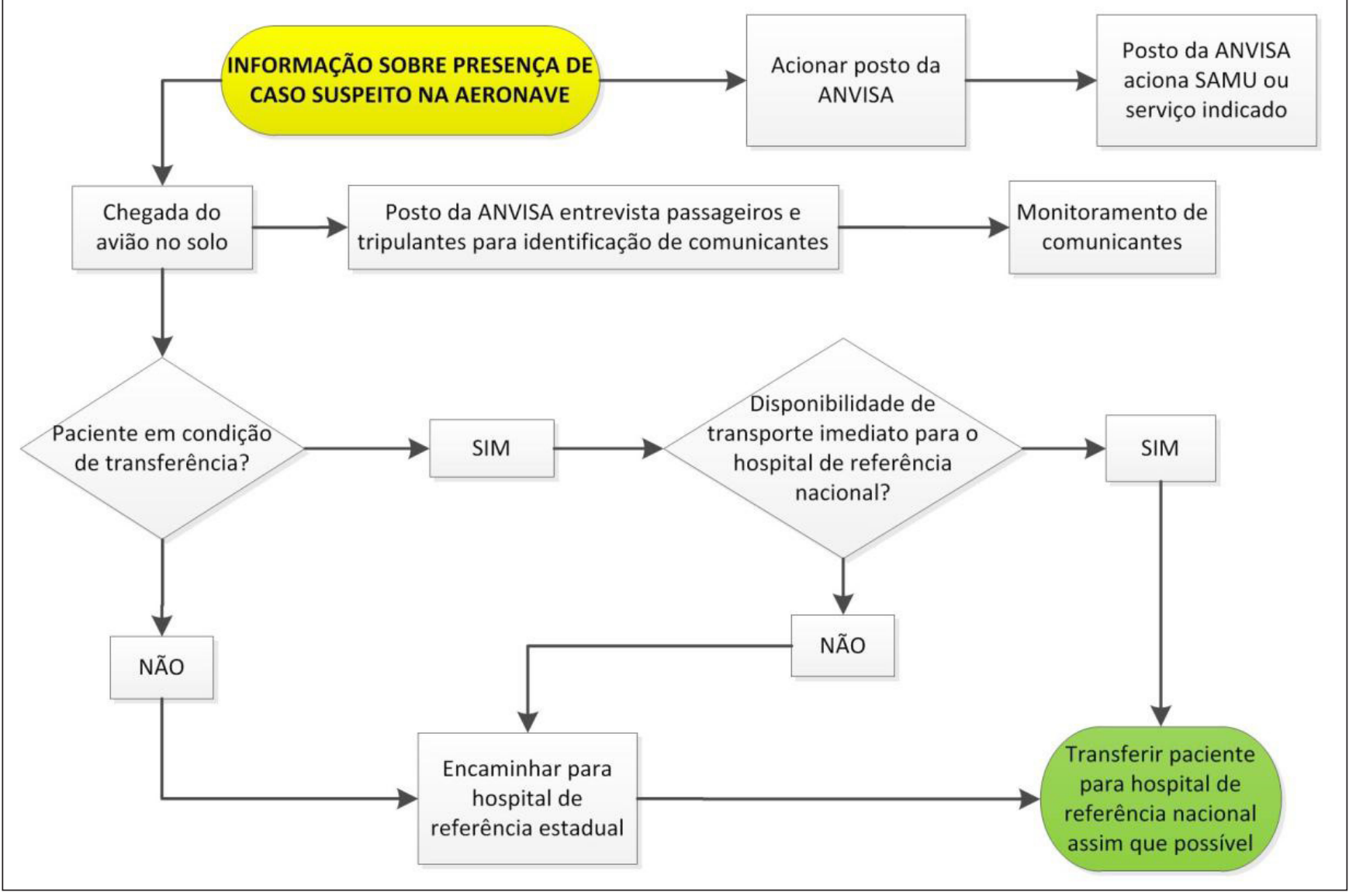

\section{Transmissibilidade de doenças em aeronaves}

Além dos já mencionados fatores que propiciam a proliferação de doenças em uma aeronave, foi constatado também que bactérias causadoras de vômitos e variadas infecções podem sobreviver por um tempo considerável em seu interior. Apoios para braços, bolsos de assentos entre outras superfícies são locais onde elas costumam habitar por vários dias.

Pesquisadores da Universidade de Auburn monitoraram as bactérias Staphylococcus aureus responsável por diversas doenças de pele - e Escherichia coli - causadora de doenças intestinais -, tendo-as aplicado em diversas superfícies encontradas no interior de uma aeronave, como os apoios, couros, bolsos e bandejas plásticas dos assentos, botões metálicos do banheiro e cortinas de plástico das janelas. Essas superfícies foram fornecidas por uma companhia aérea, e expostas, em laboratório, às condições típicas de um avião em voo. $\mathrm{O}$ resultado foi a sobrevivência por até sete dias dessas bactérias. Com isso, conclui-se que há um risco considerável de transmissão através do contato com a pele (24).

McCartney (25) aponta estudos indicando que as chances de se contrair uma gripe em uma viagem de avião giram em torno de $20 \%$. Na maioria das vezes, culpa-se o ar da cabine, que é reciclado. Porém, foi constatado que os filtros de ar de elevada eficiência - filtros HEPA, ou High Efficiency Particulate Air presentes na maioria dos jatos atuais, podem conter até 99,97\% das partículas de ar carregadas de bactérias e vírus. Além disso, o ar da cabine é renovado pelo menos 20 vezes por hora de voo. O problema maior acontece quando é necessário que o avião permaneça muito tempo em solo, sem circulação de ar, como indica um estudo feito em 1979, que analisou a transmissibilidade de doenças em uma aeronave que permaneceu nessa situação por três horas. Em decorrência, 39, ou 72\% dos 54 passageiros ficaram doentes em até dois dias, devido ao fato de um único passageiro estar gripado. 
Assim, a infecção tem a capacidade de alastrar-se numa velocidade incrível nessas condições. Foi por esse motivo que a Federal Aviation Administration (FAA), órgão responsável pela fiscalização aeronáutica nos EUA, em 2003, comunicou que companhias aéreas deveriam retirar os passageiros de suas aeronaves caso a espera excedesse trinta minutos. Todavia, a adoção dessa medida não se tornou obrigatória.

Ainda segundo McCartney (25), a maioria das transmissões acontecem não pelo ar da cabine, mas pelo contato com pessoas e objetos contaminados. Muitos dos perigos vêm das mãos, boca e nariz dos passageiros mais próximos. A área de risco compreende dois assentos de distância, atrás, à frente ou aos lados, de acordo com um estudo do jornal 'Doenças Infecciosas Emergentes', publicado pelos Centros Americanos de Prevenção e Controle de Doenças (CDCs).

Em 2009, uma pesquisa australiana analisou a contaminação de passageiros pelo vírus H1N1 - causador da gripe - em voos de longa duração. Constatou-se que $2 \%$ dos passageiros ficavam doentes durante o voo e $5 \%$, uma semana após o pouso. Além disso, essa pesquisa indicou que um passageiro sentado na área de risco anteriormente mencionada tem $7,7 \%$ de chances de contrair a doença. Já em 2002, uma pesquisa feita nos EUA sugeriu uma área de exposição muito maior. Foi observado que um passageiro afastado por sete assentos de um outro, que estava gripado, contraiu a doença, enquanto a pessoa sentada imediatamente ao lado dele, não (25).

Há algumas precauções que podem ser tomadas, no avião, para diminuir os riscos de infecções. São elas: lavar as mãos frequentemente com alguma solução baseada em álcool, já que passageiros constantemente tocam boca, nariz ou olhos após terem tocado alguma outra superfície na aeronave, como os apoios para braços dos assentos; utilizar algum tecido para limpar as bandejas antes de utilizá-las; evitar os bolsos dos assentos; abrir a passagem de ar, para que este passe à sua frente, pois o ar filtrado direcionado manterá o 'ar sujo' afastado; tentar uma troca de assento, caso haja alguém tossindo ou espirrando nas proximidades; evitar travesseiros e cobertores distribuídos pela companhia; e dormir ao menos sete horas antes da viagem, para fortalecer o sistema imunológico do organismo (26).

Um painel da Academia Nacional de Ciências (NAS), nos Estados Unidos, realizou um estudo de dois anos, coletando amostras em diversas áreas de aeroportos, em uma tentativa de descobrir seus locais mais perigosos relativamente às aglomerações de micro-organismos infecciosos. Concluiu-se que as áreas de check-in, manejo de bagagens e inspeção são as mais problemáticas, devido a uma maior aglomeração de pessoas (27).

\section{Considerações finais}

Ao analisar-se a forma como se lida com o perigo biológico hoje em dia na aviação, surge a seguinte questão: Pessoas que representam ameaça biológica estão sendo realmente identificadas? Aparentemente, não. Os critérios utilizados para identificar passageiros que possam, de alguma forma, representar perigo nesse aspecto mostram-se um tanto vagos, superficiais. Os casos abordados neste trabalho, como o do americano Patrick Sawyer, ou ainda o do liberiano Thomas Duncan, são exemplos dessa fragilidade: ambos estavam infectados com ebola e viajaram normalmente. $\mathrm{O}$ de Sawyer foi talvez o mais grave, pois ele já apresentava os sintomas da doença antes mesmo de embarcar, mas não encontrou dificuldades em tomar seus dois voos, que o colocaram em contato com 59 pessoas. Não houve quem o impedisse. Existe, portanto, uma grande falha na segurança.

Nota-se a necessidade de se estabelecer um sistema de prevenção bem definido, com regras e procedimentos mais categóricos e que atribua deveres e responsabilidades aos profissionais envolvidos no voo. Estes, então, teriam, daí em diante, a tarefa de zelar pela segurança também sob o ponto de vista biológico, recebendo o devido preparo para essa função.

Fica evidente que os regulamentos apenas citam os procedimentos a serem seguidos em caso de risco biológico a bordo, mas falta estabelecer, com clareza, o que deve ser feito para evitar, desde o princípio, esse tipo de situação. Falta uma distribuição adequada de competências, visando melhorar o gerenciamento desse risco. Quem sabe os próprios comissários de bordo poderiam receber algum treinamento específico nesse âmbito? Tudo na aviação deve ser feito com toda a cautela, seguindo à risca procedimentos muito específicos e minuciosos, visando sempre a redução dos riscos envolvidos em todas as operações. Ora, se ela é assim nos demais aspectos, no tratamento dado ao risco biológico não deveria ser diferente, já que também se trata da segurança de todos.

Os assuntos aqui abordados demonstram que a influência da aviação na vida das pessoas vai muito além do que, em um primeiro momento, se imagina. Ela abrange aspectos de segurança que vão além do risco de acidentes aeronáuticos e que, muito embora sejam menos importantes que estes, não devem ser negligenciados. Isso pôde ser muito bem observado quando o mundo assistiu, em 2014, à crise do vírus ebola, que surgiu em território muito limitado do oeste africano, mas tomou dimensões muito maiores a partir do momento em que começou a se espalhar por outros continentes, por meio da aviação, que cumpria nada mais que seu papel de proporcionar a ligação entre os povos. A presença, porém, de passageiros infectados 
com esse vírus mortal colocou em risco a saúde pública em todos os países do planeta.

Felizmente, agora em 2015, a doença parece estar sob controle e deixou de ser motivo de tantas preocupações como foi no ano passado, mas acabou revelando uma série de falhas de segurança na forma como a aviação é atualmente conduzida. Essas falhas devem servir como ponto de partida para o desenvolvimento de um sistema mais eficaz no combate à disseminação de doenças pelo transporte aéreo, antes do possível surgimento de uma outra situação de risco mundial, talvez ainda mais grave que a do ebola.

\section{Referências}

1. Brasil. Ministério do Trabalho e Emprego. Normas Regulamentadoras de Segurança e Medicina do Trabalho. NR 32 Segurança e Saúde no Trabalho em Estabelecimentos de Assistência à Saúde [Internet]. [citado em 08 de fevereiro de 2015] Disponível em: <http://www.mte.gov.br>.

2. ACRP. Airport Cooperative Research Program. Infectious Disease Mitigation in Airports and on Aircraft. Washington D.C; 2013. 30.

3. Cardoso M. Príons [Internet]. [citado em 01 de março de 2015] Disponível em: <http://www.infoescola.com/ bioquimica/prions/>.

4. Berkow R, Beers MH, Bogin RM, Fletcher AJ. Manual Merck de Informação Médica: Saúde para a Família. Disponível em: $<$ http://www.manualmerck.net/?id=311>. Acesso em: 09 mar. 2015.

5. Brasil. Código Brasileiro de Aeronáutica. 1986. [citado em 09 de março de 2015] Disponível em: <http://www.planalto. gov.br/ccivil_03/leis/L7565.htm>.

6. G1. Por Lei, Piloto Pode Barrar Passageiro Doente; Veja Como Evitar Problemas [Internet]. [atualizado em agosto de 2013; citado em 10 de março de 2015] Disponível em: $<$ http://g1.globo.com/turismo-e-viagem/noticia/2013/08/porlei-piloto-pode-barrar-passageiro-doente-veja-como-evitarproblemas.html>.

7. Tecmundo. Qual é a sensação de andar em velocidades absurdas? [Internet]. [citado em 06 de abril de 2015] Disponível em: < http://www.tecmundo.com.br/ciencia/16109qual-e-a-sensacao-de-andar-em-velocidades-absurdas-.htm>.

8. IATA. Medical Manual. 6ª ed. Montreal; 2013. 88.

9. Brasil. ICA 100-12: Regras do Ar e Serviços de Tráfego Aéreo. Brasília: Estado-Maior da Aeronáutica; 2013.

10. ICAO. Annex 9. 13ํㅡㄹ ed. Montreal; 2011. 90.

11. Brasil. Ministério da Aeronáutica. AIP. Publicação de Informação Aeronáutica. 2ª ed. 2014.

12. Folha Política. Ebola é emergência internacional de saúde pública, declara OMS [Internet]. [atualizado em agosto de 2014; citado em 31 de Fevereiro de 2015] Disponível em: $<$ http://www.folhapolitica.org/2014/08/ebola-e-emergenciainternacional-de.html>.

13. INFO. OMS Declara Ebola Como Emergência Pública de Alcance Internacional [Internet]. [atualizado em agosto de 2014; citado em 15 de março de 2015]. Disponível em: <http://info.abril.com.br/noticias/ciencia/2014/08/omsdeclara-ebola-como-emergencia-publica-de-saude-de-alcanceinternacional.shtml>.
14. Saconi A. Por Medo do Ebola, British Airways Cancela Voos Para Serra Leoa e Libéria. [Internet]. [citado em 15 de março de 2015] Disponível em: <http://noticias.r7.com/ saude/por-medo-do-ebola-british-airways-cancela-voos-paraserra-leoa-e-liberia-05082014>.

15. O Dia. Emirates Suspende Voos à Guiné Por Epidemia De Ebola [Internet]. [citado em 15 de março de 2015] Disponível em: <http://odia.ig.com.br/noticia/mundoeciencia/2014-08-02/ emirates-suspende-voos-a-guine-por-epidemia-de-ebola. html>.

16. Nye J. Ebola victim who sparked fears of a worldwide outbreak was American: Father who died of incurable virus in Nigeria after taking international flight was going to visit his children in Minnesota [Internet]. [citado em 25 de março de 2015] Disponível em:< http://www.dailymail.co.uk/news/ article-2709180/Ebola-victim-sparked-fears-global-outbreakAmerican-Father-died-incurable-virus-Nigeria-takinginternational-flight-going-visit-children-Minnesota.html>.

17. Opera Mundi. Nigéria suspende voos de companhia aérea na qual viajou vítima do ebola [Internet]. [citado em 25 de março de 2015] Disponível em: <http://operamundi.uol.com. $\mathrm{br} /$ conteudo/noticias/37217/nigeria + suspende+voos + de + comp anhia+aerea+na+qual+viajou+vitima+do+ebola.shtml $>$.

18. Corrêa A. Risco de Ebola Chegar ao Brasil é de 5\%, Diz Estudo [Internet]. [citado em 22 de março de 2015] Disponível em: <http://www.bbc.co.uk/portuguese/ noticias/2014/10/141007_ebola_contagio_estudo_ac.shtml $>$.

19. Deutsche Welle. Morre primeiro paciente diagnosticado com ebola nos EUA [Internet]. [citado em 25 de março de 2015] Disponível em: <http://www.dw.de/morre-primeiropaciente-diagnosticado-com-ebola-nos-eua/a-17983179>.

20. Botelho G. U.S Ebola patient: The travels and health travails of Thomas Eric Duncan [Internet]. [citado em 25 de março de 2015] Disponível em: <http://edition.cnn.com/2014/10/01/ health/us-ebola-patient/>.

21. Mundasad S. Ebola: testes em aeroportos não detectam infectados sem sintomas [Internet]. [citado em 25 de março de 2015] Disponível em: < http://www.bbc.co.uk/portuguese/ noticias/2014/10/141010_ebola_aeroportos lab $>$.

22. Sircus M. Are ebola tests reliable? [Internet]. [citado em 25 de Março de 2015] Disponível em: < http://drsircus.com/ medicine/ebola-tests-reliable $>$.

23. Brasil. Ministério da Saúde. Secretaria de Vigilância em Saúde. Protocolo de Vigilância e Manejo de Casos Suspeitos de Doença pelo Vírus Ebola. Brasília; 2014. e15.

24. EXAME. Estudo: Bactérias Podem Sobreviver até Uma Semana em Aviões [Internet]. [citado em 17 de março de 2015]. Disponível em: < http://exame.abril.com.br/tecnologia/ noticias/estudo-bacterias-podem-sobreviver-ate-uma-semanaem-avioes $>$.

25. Mccartney S. Where Germs Lurk on Planes [Internet]. [citado em 17 de março de 2015]. Disponível em: < http:// www.wsj.com/news/articles/SB1000142405297020405 8404577108420985863872 ? mg $=$ reno64 - wsj\&url $=$ http \% 3 A \%2F\%2Fonline.wsj.com\%2Farticle\%2FSB $10001424052970204058404577108420985863872 . h t m l>$.

26. Seaney R. How to Avoid Getting Sick on a Plane [Internet]. [citado em 17 de março de 2015]. Disponível em: <http://abcnews.go.com/Travel/avoid-sick-plane/ story? $\mathrm{id}=21127450>$.

27. Gerencher CL. Research on the Transmission of Disease in Airports and on Aircraft: Summary of a Symposium [Internet]. TR News Magazine; 2011 [Atualizado em fevereiro de 2011; citado em 17 de março de 2015]. Disponível em: <http://onlinepubs.trb.org/onlinepubs/trnews>. 